\title{
Molecular defects in the mannose binding lectin pathway in dermatological disease: Case report and literature review
}

\author{
Christopher Miller ${ }^{2}$, Sara Wilgenbusch ${ }^{3}$, Mini Michael ${ }^{2}$, David S Chi ${ }^{2}$, George Youngberg ${ }^{1,4}$, \\ Guha Krishnaswamy $y^{2,3,4^{*}}$
}

\begin{abstract}
Mannose-binding lectin (MBL) and the Mannose-binding lectin-associated serine proteases (MASPs) are an essential aspect of innate immune responses that probably play an important but understudied role in cutaneous function. The MBL-MASP pathway appears to exert its primary role by assisting in the clearance of apoptotic skin cells (thus preventing accumulation and a subsequent autoimmune response) and promoting opsonophagocytosis of invading pathogens, limiting their dissemination. Deficiencies of the pathway have been described and are associated with infectious, autoimmune and vascular complications. However, the role of this pathway in dermatological disease is essentially unexplored. We describe 6 patients presenting with recurrent inflammatory and/or infectious skin conditions who also demonstrated severely low MBL levels. One patient also had a defect in the MASP2 gene. Genotype analysis revealed specific point mutations in the MBL2 promoter in all 6 patients and a variant MASP-2 gene in one patient. Five patients presented recurrent pustular skin infections (cellulitis, folliculitis and cutaneous abscess). A case of Grover's disease and one forme fruste of Behcet's syndrome (orogenital ulcers) were also observed. The patients responded to antimicrobial therapy, although in some, recurrence of infection was the rule. It appears that MBL deficiency may contribute to recurrent skin infections and to certain forms of inflammatory skin disease. The mechanisms may relate to the role of this pathway in innate immunity, removal of apoptotic cells and in immune complexes. Further study of MBL pathway defects in dermatological disease is required.
\end{abstract}

\section{Introduction}

The skin represents the largest organ of the innate immune system, composing not only a physical barrier but also containing numerous elements important in the immunological response against invading pathogens (e.g. keratinocytes, macrophages, Langerhans cells, dendritic cells, dermal fibroblasts). Damage to this barrier predisposes the body to a more susceptible environment for microbial dissemination, while improper immune surveillance can be a triggering factor for several inflammatory skin diseases [1]. This is an intricately orchestrated defense system constituted by a local response at the level of the epidermis and dermis, as well as by systemic involvement, with migration of additional immune cells to the site of antigenic stimulus.

\footnotetext{
* Correspondence: krishnas@etsu.edu

${ }^{2}$ Internal Medicine, Quillen College of Medicine, East Tennessee State University, Johnson City, TN 37614, USA
}

A member of the collectin group of pattern recognition receptors, mannose-binding lectin (MBL) is part of the innate immune system, a primordial defense mechanism that serves as the initial response to host invasion by pathogens in an antibody-independent fashion (Figure 1). This is achieved through direct opsonization of bacteria, recruitment of phagocytic cells that promote phagocytosis of pathogens, along with complement activation and immunomodulatory cytokine production that promote chemotaxis and recruitment of inflammatory cells, thereby limiting pathogenic spread. Defective MBL production is regarded as the most common immune deficiency in the general population, affecting approximately 5-7\% of individuals [2], although some descriptions have delineated higher figures among Caucasians (up to 30\%) [3]. The implications of low MBL levels have been the target of a large volume of research, with an unequivocal influence on host 


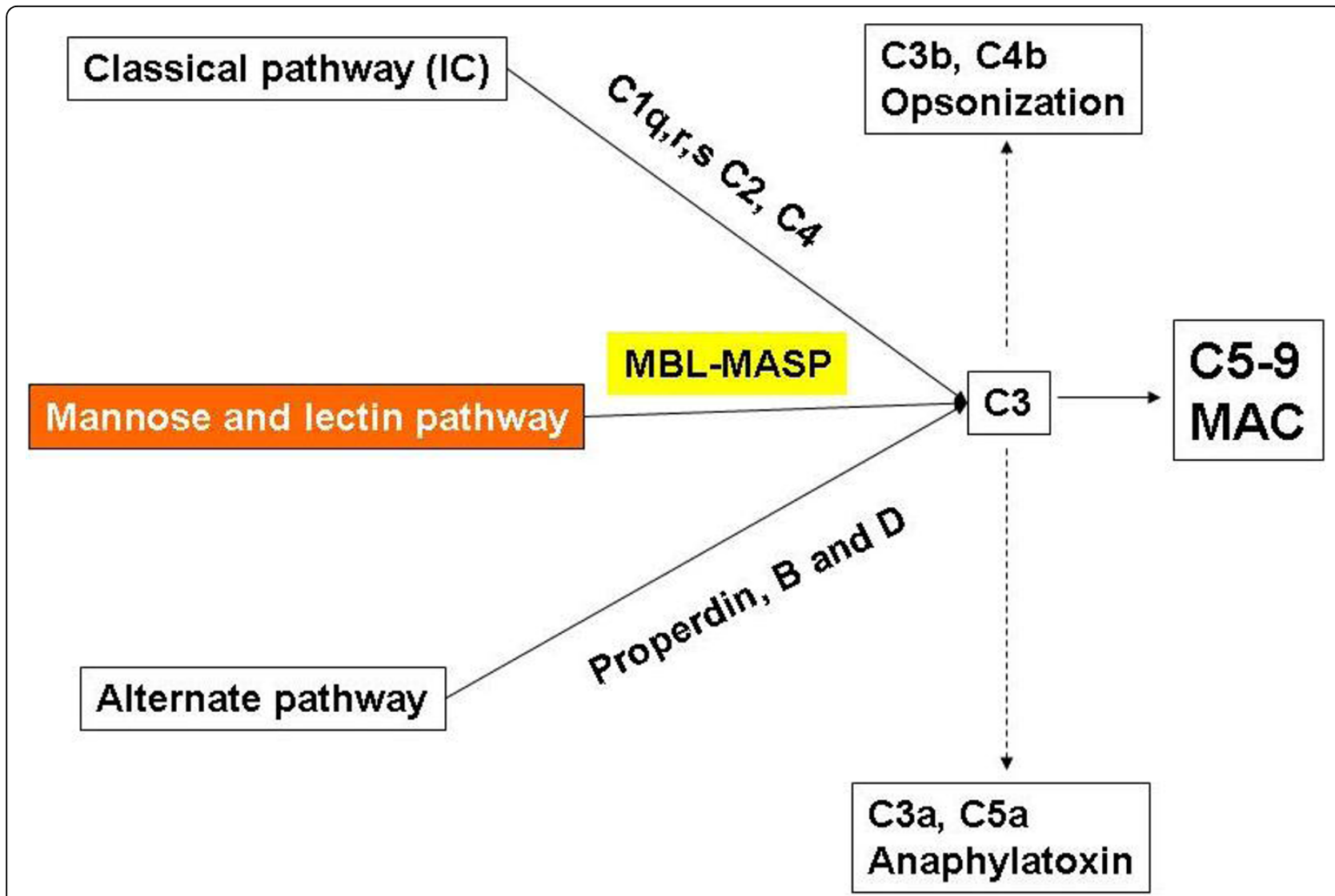

Figure 1 Schematic representation of the three complement activation pathways, converging to cleave C3. Classical pathway (activated by immune complexes), MBL-pathway (activated by bacterial sugars such as mannose) and the alternate pathway (activated even in the absence of antibody), result in formation of the C3 convertase, which culminates in C3 activation. After this occurs, C3b will opsonize the surface of the pathogen, with subsequent phagocytosis. Further progression of the cascade leads to the activation of C5-9 and to the formation of the membrane attack complex (MAC), lysing the microbe/cell. Byproducts of these pathways include anaphylotoxins C3a and C5a, recruiting leukocytes which contribute to the inflammatory response.

susceptibility to a variety of recurrent infectious processes and autoimmune disorders. However, propensity to dermatological disease has not been explored to any great extent. One report using MBL-deficient mice demonstrated upregulation of inflammatory cytokines and chemokines, thinning of the dermis and epidermis, as well as eschar separation, in response to burn injury [4]. Other investigators have suggested that diseases such as atopic dermatitis, that present defects in innate immunity, may have a defective MBL response [5]. Nevertheless, the role of MBL-MASP pathway defects in dermatological disease is sparse, and we believe our report to be the first to link MBL deficiency to recurrent infectious and inflammatory skin disease in 6 patients. Further studies in this area are obviously sorely required. This is especially important as treatment with recombinant MBL may soon be available and may assist some patients with otherwise refractory or serious dermatological disease.

\section{Case Presentation}

The study was approved by the Institutional Review Board (East Tennessee State University) and the Research and Development Committee of the James $\mathrm{H}$. Quillen Veterans Affairs Medical Center in Mountain Home, Tennessee. The records of the patients were reviewed and appropriate data collected. Immunoglobulin assays were carried out in commercial laboratories by traditional techniques. MBL genotyping and functional assays were carried out by the IBT laboratories, Lenexa, Kansas. MBL genotypes were assigned as per Figure 2. Tables 1 and 2 list the laboratory results and immunological evaluation in these patients.

\section{Patient 1}

A 39-year-old woman complained of recurrent pustular eruption of her upper extremities and chronic allergic rhinitis. Immunological evaluation demonstrated the following: IgG levels were slightly decreased, but IgG 


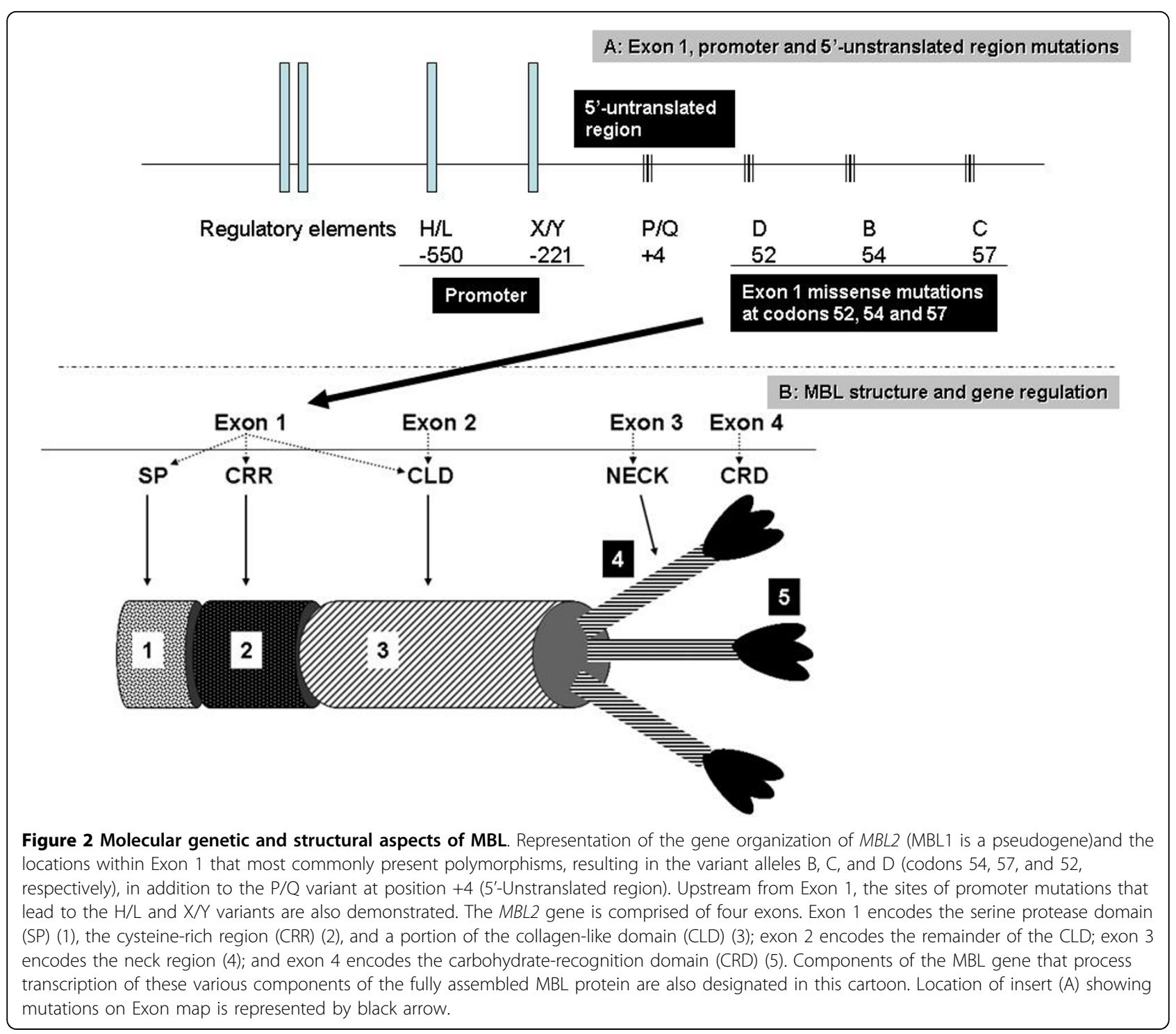

subclass levels were all normal. The patient had detectable/robust responses to $6 / 14$ pneumococcal serotypes (Table 1). Further work-up yielded a low level of MBL at $<50 \mathrm{ng} / \mathrm{ml}$ (reference: $>100 \mathrm{ng} / \mathrm{ml}$ ), as well as an impaired MBL pathway functional test using the $\mathrm{C} 4 \mathrm{~b}$ deposition assay. Genotyping showed the HYPD/HYPD variant of $M B L 2$ and wild-type MASP-2 genotype (A/A) (Table 2).

\section{Patient 2}

A 61-year-old man presented with recurrent folliculitislike eruptions of the skin. His history was significant for a prior history of infection of the cheek with methicillin-resistant Staphylococcus aureus (MRSA) treated with minocycline. Six years earlier, he had suffered infection of a pacemaker site with MRSA, which had spread to his upper extremities, but was ultimately controlled with antibiotics. He denied intravenous drug use. Physical examination revealed a $1-\mathrm{cm}$ indurated nodule over his left cheek, a $5 \times 3 \mathrm{~cm}$ hyperpigmented patch over his left ankle, and scattered areas of erythema over his anterior chest wall and dorsum of his legs. MBL level was $<50 \mathrm{ng} / \mathrm{ml}$, while all classes of immunoglobulins were within normal range (Table 1). MBL genotyping revealed the LYPB/HYPD haplotypes. MASP-2 genotype was the wild type (A/A). MBL functional pathway test was impaired (Table 2). A skin biopsy of the folliculitislike rash (Figure 3, IV) was performed, revealing Grover's disease (transient acantholytic dermatosis). Topical therapy was instituted with triamcinolone.

\section{Patient 3}

A 47-year-old woman presented with a pustular rash (Figure 3, I A, B and 3, I C) on her skin (face, back, forearms and leg) and pustular inguinal eruptions; on 
Table 1 Outline of additional immune deficiencies encountered in the patient group

\begin{tabular}{|c|c|c|c|}
\hline Patient & Laboratory assay & Patient value & Reference range \\
\hline \multirow[t]{4}{*}{$\# 1$} & Total immunoglobulin G (lgG) & $768 \mathrm{mg} / \mathrm{dL}$ & $791-1643 \mathrm{mg} / \mathrm{dL}$ \\
\hline & IgG subclasses & Normal & \\
\hline & $\begin{array}{l}\text { Robust response to } \\
\text { pneumococcal serotype }\end{array}$ & $6 / 14$ & $>8 / 14$ \\
\hline & Functional MBL pathway (C3b deposition assay) & 2.02 & $>5.1$ \\
\hline \multirow[t]{2}{*}{ \#2 } & Immunoglobulin and complement levels & Normal & \\
\hline & Functional MBL pathway (C3b deposition assay) & 2.22 & $>5.1$ \\
\hline \multirow[t]{2}{*}{ \#3 } & C4 level & Mild deficiency (1 null allele out of 4) & 4 functioning alleles \\
\hline & Functional MBL pathway (C3b deposition assay) & 2.04 & $>5.1$ \\
\hline \multirow[t]{4}{*}{ \#4 } & Immunoglobulin and complement levels & Normal & \\
\hline & C-reactive protein & $10 \mathrm{mg} / \mathrm{L}$ & $<6 \mathrm{mg} / \mathrm{L}$ \\
\hline & Antinuclear antibody & 1/8 (weakly positive) & $<1 / 8$ \\
\hline & Functional MBL pathway (C3b deposition assay) & 2.10 & $>5.1$ \\
\hline \multirow[t]{2}{*}{ \#5 } & Immunoglobulin and complement levels & Normal & \\
\hline & Functional MBL pathway (C3b deposition assay) & 2.18 & $>5.1$ \\
\hline \multirow[t]{2}{*}{ \#6 } & $\lg G 3$ & $34 \mathrm{mg} / \mathrm{dL}$ & $41-129 \mathrm{mg} / \mathrm{dL}$ \\
\hline & Functional MBL pathway (C3b deposition assay) & Not available & \\
\hline
\end{tabular}

Table 2 Summary of clinical scenarios and respective genotyping results

\begin{tabular}{lll}
\hline Patient & Clinical condition & MBL2 \\
\hline$\# 1$ & Rhinoconjunctivitis and recurrent upper extremity skin infections & MASP-2 \\
$\# 2$ & History of MRSA pacemaker infection and recurrent folliculitis & A/A \\
$\# 3$ & Recurrent S. aureus folliculitis & LYPB/HYPD \\
$\# 4$ & Fungal folliculitis & LYPB/HYPD \\
$\# 5$ & Forme fruste of Behçet's disease & LXPA/LYPB \\
$\# 6$ & Recurrent lower extremity cellulitis and ulcerations & LXPA/LYPB \\
\hline
\end{tabular}

one occasion she had developed a vulvar infection with abscess formation requiring drainage. Past medical history included recurrent rhinosinusitis and anxiety disorder. Biopsy of the lesion showed pustular changes with neutrophilic infiltration, but did not reveal lymphocyte infiltration. A culture from a lesion on her forearm was positive for Staphylococcus aureus. The patient responded to administration of cefadroxil and minocycline, with remission and frequent relapses. Laboratory workup revealed mild $\mathrm{C} 4$ deficiency and an undetectable IgE level (Table 1). Assays were unremarkable for ANA, ESR, rheumatoid factor, hepatitis viruses, and HIV. The MBL level was exceptionally low at $<50 \mathrm{ng} / \mathrm{ml}$, and her MBL functional pathway was impaired. MBL genotyping revealed a LYPB/HYPD haplotype, while MASP-2 was wild-type (Table 2).

\section{Patient 4}

49-year-old woman with complaints of a blistering skin eruption and hyperpigmentation for the past 6 years; the lesions were thick, tender, indurated, and presented with yellow-green secretion. Her past medical history included recurrent impetigo, perennial rhinitis, and ulcerative colitis. On exam, a 1-inch area of induration and erythema was observed over her chin (Figure 3II A and 3II B); there were multiple scattered pustular lesions over the forearms, some ulcerated. Encrusted pustules were also observed over her scalp, face, back and legs. Work-up yielded a weakly positive ANA and an elevated CRP (10 mg/L) (Table 1). MBL levels were low at $<50$ $\mathrm{ng} / \mathrm{ml}$. Punch biopsy from her forearm (Figure 3, II C) revealed histopathology and morphology compatible with Candida sphaerica, although the possibility of Trichophyton rubrum was also raised; cultures were attempted from a specimen but no growth was observed. An aspirate of one of the pustules grew Sphingomonas paucimobilis. Terbinafine and levofloxacin were given, and her eruption resolved. Genotyping revealed LXPA/LYPB for MBL and A/G for MASP-2 (Table 2). The MBL functional assay was also impaired.

\section{Patient 5}

A 48-year-old woman presented with painful orogenital ulcerations. She had a family history of documented Behcet's disease (BD) in her father and brother and she was concerned she may have the disease. She was 

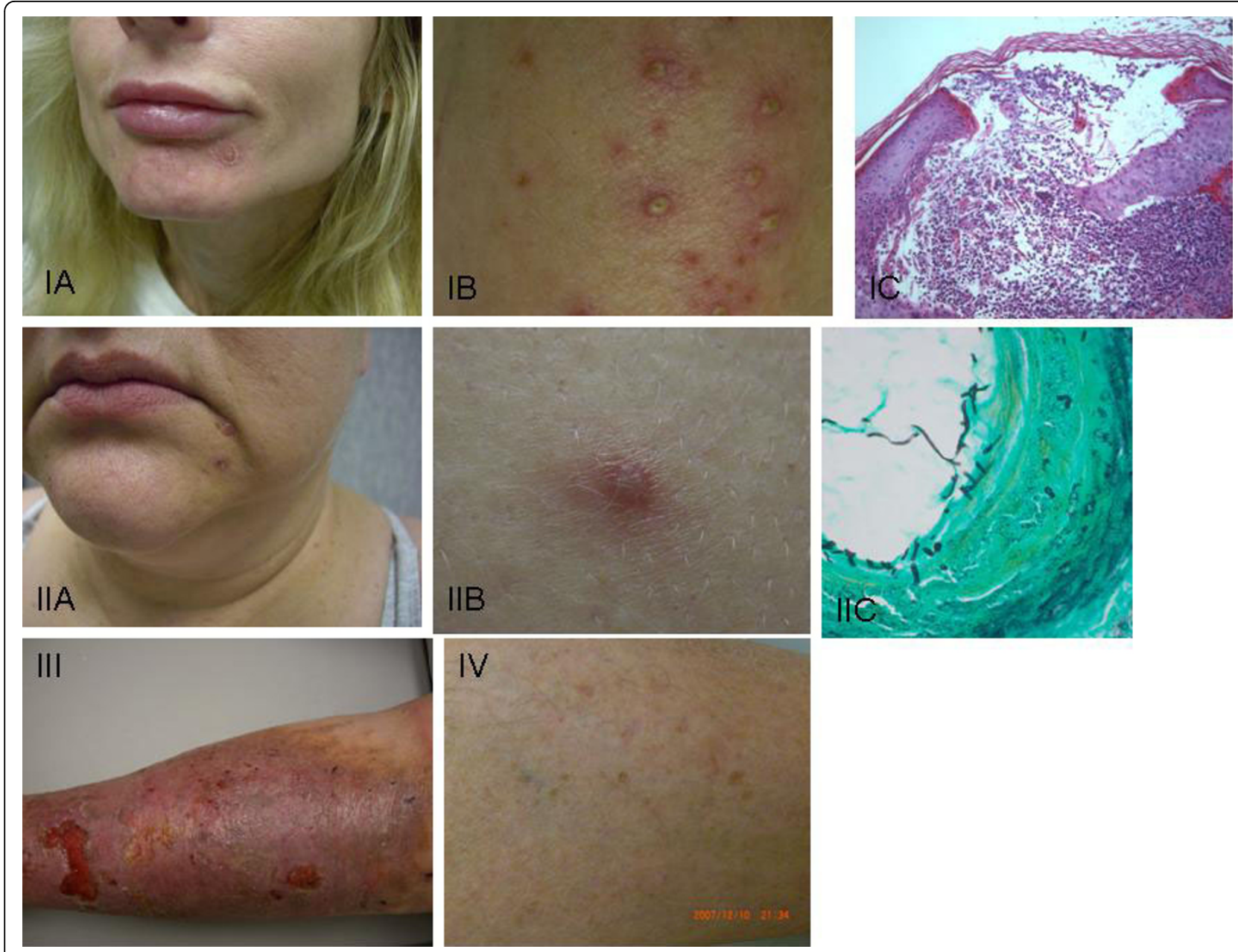

Figure 3 Patients with MBL deficiency and dermatological disease. Figures । A, B and C demonstrates pustular skin eruption, with biopsy showing neutrophilic inflammation in patient \#3. Figures II A, B and C demonstrate fungal folliculitis with PAS stain (C), demonstrating fungal hyphal elements in patient \#4. Figure III shows lower extremity cellulitis and inflammatory ulcer of patient \#6, and figure IV demonstrates folliculitis-like rash of patient \#2 with Grover's Disease and history of recurrent staphylococcal skin infections.

uncertain as to whether she was of Melungeon descent (peoples of Tri-racial descent who have lived in the South-Eastern United States: these include European, African/Middle Eastern/Turkish and Native American). Pertinent other history included severe polyarthralgia (hands, wrists, arms, knees, and ankles) over the past 8 years.

A pathergy test was negative. Immunoglobulin levels, ESR, and CRP were unremarkable. Assays for hepatitis viruses, HIV, rheumatoid factor, Herpes simplex, and lupus anticoagulant were negative (Table 1). Ophthalmologic evaluation did not demonstrate the characteristic uveitis. She was treated with a pulse of oral glucocorticoids and placed on long term hydroxychloroquin. After 5 months, oral and genital ulcerations had resolved. Due to the clinical response to therapy but insufficient diagnostic criteria, she was diagnosed with a forme fruste of BD. Further work-up established an MBL level $<50 \mathrm{ng} / \mathrm{ml}$ and a deficient MBL functional pathway (Table 1). Genotyping revealed an LXPA/LYPB haplotype for MBL and A/A for MASP-2 (Table 2).

\section{Patient 6}

A 56-year-old Caucasian man complained of recurrent bilateral lower extremity cellulitis and ulcerations, requiring hospitalization and parenteral antibiotic administration. History included factor V Leiden mutation with recurrent lower extremity deep venous thromboses and recurrent MRSA urinary tract infections. He had undergone numerous abdominal procedures, with recurrent enterocutaneous fistulae and wall abscesses. Abdominal exam revealed wall ulceration with serosanguineous drainage and surrounding erythema. His lower extremities presented ochre dermatitis, bilateral $+/ 4$ 
edema below the knee; there were 2 ulcerations on the anterior portion of his left leg, measuring $1 \times 1 \mathrm{~cm}$ and $2 \times 3 \mathrm{~cm}$ (Figure 3, III). A lower extremity ultrasound showed a left-sided nonocclusive chronic thrombus in the femoral and popliteal veins. Total levels of immunoglobulins were normal (except for a small decrease in IgG3), as were C2 and C4 (Table 1). Anticardiolipin antibody was negative. The patient had a low level of MBL (<50 ng/ml), genotyping showing a LYPB/LYPB polymorphism for MBL and a wild-type MASP-2 (Table 2 ). The patient's abdominal wall culture grew cephalosporin-sensitive Staphylococcus aureus; cultures from his lower extremity ulcerations were positive for Pseudomonas aeruginosa. The patient responded to antimicrobials, compression stockings and topical Tacrolimus ${ }^{\odot}$.

\section{Disscussion}

The MBL-MASP pathway of complement activation results in multiple beneficial effects in the innate response to pathogens. Deficiencies of the MBL-MASP pathway have been linked to recurrent and serious infections, atopic disease, and autoimmunity, as well as to cardiovascular pathology. However, the role of this pathway in dermatological disease has not been studied adequately.

The circulating MBL-2 protein is an oligomeric molecule formed by three identical polypeptides which spiral around each other in a tight helix to form a subunit, several of which link together to compose higher-order oligomers (Figure 2). It is through the carbohydraterecognition domain (CRD) that pathogen-associated molecular patterns (PAMPs) are recognized and bound, with biological activity occurring through clustering of CRDs and multiple carbohydrate binding to the widelyspaced, repetitive sugars on the surface of pathogens [6-8]. Upon binding to PAMPs, the MBL pathway and MASP recruitment are activated. MASP-2 is analogous to $\mathrm{C} 1 \mathrm{~s}$ as it forms $\mathrm{C} 3$ convertase by sequentially cleaving $\mathrm{C} 4$ and $\mathrm{C} 2$. Deposition of $\mathrm{C} 3 \mathrm{~b}$ on the microbial cell surface is the common point between the 3 complement pathways, after which either opsonophagocytosis will occur or the membrane attack complex will form pores in the cell wall and lead to osmotic lysis (Figure 1).

There are three functional single nucleotide polymorphisms within exon 1 of the $M B L 2$ gene which lead to low serum MBL levels. The A allele is also termed "wild-type" and is usually associated with normal MBL levels. The variant alleles (B, C and D) are collectively termed $\mathrm{O}$ alleles and confer a distorted molecular structure, as well as low serum MBL. There are seven MBL2 haplotypes, 4 of which are associated with decreased MBL levels (LYPB, LYQC, HYPD, and LXPA), the other 3 (HYPA, LYPA, and LYQA) producing normal levels [9]. Serum MBL will be about one-fifth of normal range in heterozygotes and less than $2 \%$ in homozygotes or compound heterozygotes [10].

Alternative splicing and polyadenylation of the MASP2/MAp19 gene lead to encoding of MASP-2 and MAp19. Recent reports have identified a mutation in exon 3 of this gene leading to the exchange of aspartate with glycine at position 105 (D105G) within the CUB1 domain, causing impaired binding to $\mathrm{MBL}$, and also low circulating plasma levels of MASP-2 [11,12]. Wild-type genotypes (AA) present with normal serum levels of MASP-2, while homozygotes for the mutation (GG) will display little or no lectin pathway activity. Heterozygous genotypes (AG) confer approximately half the amount of circulating MASP-2.

The patient in Case 1 manifested recurrent upper respiratory tract infections, most likely of an occupational nature, in addition to repeated skin findings. The exact nature of her skin condition was not clearly elucidated, but the fact that she presented a good response to antihistamine and steroid therapy suggests atopy, reinforced by concomitant respiratory tract involvement. The association between recurrent upper respiratory infections and MBL deficiency has been grounds for debate by a number of studies [13-16]. MBL promotes complement-mediated killing of a number of upper respiratory pathogens $[17,18]$. In the case of pneumococcus, MBL has an ancillary part in promoting opsonophagocytosis, and low serum levels have been associated with increased mortality [19]. Our patient displayed mild deficiency in total IgG with normal subclasses, manifest through a diminished antipneumococcal immunoglobulin production, which may occur in the absence of a specific subclass deficiency [20].

In Case 2, the development of MRSA infection at the site of pacemaker placement may have been a trigger for recurrent skin findings, with several failed attempts at eradicating the organism. MBL participates in firstline defense against $S$. aureus via opsonophagocytosis by macrophages and neutrophils [21]. The MBL-MASP complex has a significant role in increasing C3b deposition on the surface of $S$. aureus [22], contributing to an increase in its engulfment by neutrophils. In addition, $\mathrm{C} 3 \mathrm{~b}$ combines with factor $\mathrm{B}$ to generate the alternative pathway convertase $(\mathrm{C} 3 \mathrm{bBb})$, which promotes further breakdown of C3b [23]. Thus, the lectin and alternative pathways have developed mutual amplification loops [24], although experimental evidence suggests that the alternative pathway has a much greater influence on controlling staphylococcal bacteremia than the lectin or classical pathway [25]. In addition, MBL triggers macrophage release of cytokines in response to bacterial invasion, enhancing neutrophilic activity. MBL is a modulator of inflammation, interacting with toll-like receptors in NF- $\kappa \mathrm{B}$-dependent production of TNF- $\alpha$; 
the latter is a crucial element in host defense, and its deficiency impairs recruitment of neutrophils and phagocytosis [26]. MBL-null mice incubated with intravenous $S$. aureus had a blunted production of TNF- $\alpha$ and interleukin-6 (IL-6) reversible by pretreatment with recombinant human MBL (rhMBL) [21]. The influence of the C4 deficiency in our third patient is questionable, highlighted by a murine study by Cunnion et al. showing similar mortality from bacteremia caused by encapsulated $S$. aureus as compared to controls with normal C4 [25].

A potentially confounding factor in Case 2 is the concurrent diagnosis of Grover's disease, which has been associated with immunodeficiency [27]. Although usually self-limited, one-third of patients may be refractory to therapy. Of note, success in treating this condition with antibiotics or antimycotics should raise questions about the veracity of the diagnosis [27].

The role of MBL deficiency in recurrent fungal folliculitis is not entirely clear, but it is likely that fungal mannan may be able to activate the complement cascade that then leads to activation of a phagocytic and cellular immune response. Defense against dermatophyte infection relies greatly on cell-mediated immunity to destroy the stratum corneum in which the pathogens reside (seen as how complement and humoral elements have limited access to this layer), aided by a Th1-type delayed hypersensitivity reaction [28-31]. MBL has been shown to have a strong binding affinity for Candida albicans and acts in first-line defense against this organism, increasing C3 deposition on its surface and hence phagocytosis by neutrophils [32,33].

Due to the diagnosis of BD in 2 other family members, a possible familial clustering was suggested in Case 5, as this disease has a strong genetic influence and is distributed within certain geographic locations (i.e. Mediterranean and Asia) [34,35]. Unfortunately, an accurate familial background was not provided by the patient. A potential role for microorganisms (e.g. streptococci, viruses) has been suggested in the etiopathogenesis of $\mathrm{BD}$, due to a hyperactive response to bacterial antigens and/or heat shock proteins in an already proinflammatory state $[36,37]$. Hence, innate immunity would be essential in limiting invasion and an exaggerated immune response, with MBL deficiency representing a susceptibility and severity factor in BD [37]. Apart from impairing local defenses (potentially facilitating recurrent oral ulcers), low MBL levels allows a more constant pathogenic stimulation, leading to immune cell infiltration and a Th1-type cytokine profile (with increased levels of IL12 and interferon- $\gamma$ ) [36,37]. In addition, MBL has an important role in clearance of apoptotic cells (MBL is recruited from noncutaneous sources to bind apoptotic keratinocytes and induce their uptake by dendritic cells)
[38], the accumulation of which can favor autoimmunity, as the release of intracellular components triggers inflammatory cytokine production and development of reactive clones, leading to autoantibody formation $[39,40]$. In the specific case of BD, there are large numbers of PMNs located within mucocutaneous lesions, and MBL deficiency contributes to impaired clearance of these cells after they undergo apoptosis, precipitating the immune response described [37]. Of note, the negative pathergy test (intradermal saline injection looking for a granulomatous reaction at the injection site) displayed by our patient does not exclude the diagnosis, as it is only positive in around $30 \%$ of cases.

In addition to recurrent infections with $S$. aureus and $P$. aeruginosa, against which MBL plays a role in primary defense, the patient in Case 6 presented with complicated postoperative courses. Postoperative infections have already been shown to occur at a greater rate in MBL-deficient patients (haplotype $\mathrm{A} / \mathrm{O}, \mathrm{O} / \mathrm{O}$ in exon 1 and $\mathrm{AX} / \mathrm{AX}$ ), and preoperative serum levels are actually a form of identifying patients at risk [41,42]. Now, while MBL deficiency has been shown to predispose to arterial thrombosis in patients with autoimmune disorders, no increased risk for development of venous thrombosis was demonstrated [43]. But, in this particular case, his hypercoagulable condition is the most likely culprit.

The major limitation in our study is the small number of cases, the lack of appropriate controls and the high frequency of MBL deficiency in the population. This might suggest that these findings are coincidental and that MBL deficiency may have no relationship to the infections experienced by the reported group of patients. Nevertheless, we feel this report is among the first to connect recurrent and sometimes serious skin infections and inflammatory conditions to the MBL-MASP pathway. We hope this report will lead others to look for these defects. Finally, this series of case reports could lead to a better-designed study to evaluate the prevalence and significance of MBL-MASP pathway defects in patients with cutaneous infections. Also of note, it is likely that in a subset of patients, MBL deficiency may need to be accompanied by yet another immune defect, such as in the classical complement, humoral immune or phagocytic pathways to manifest infection (such as has been demonstrated in patients with chemotherapyrelated infection). The pathogenic role of MBL-MASP pathway in infectious and inflammatory dermatoses needs to be defined and more studies are required.

A number of our patients would be likely candidates for MBL replacement therapy, particularly those who did not display a satisfactory response to conventional therapies. Several trials have met with promising results in Europe, but use of recombinant human MBL (rhMBL) in the United States is not yet approved. 
Recently, a second-generation plasma-derived MBL (pMBL) product has been manufactured and is undergoing phase II trials. Work with stem cell preparations has given ground to new hypotheses suggesting possible cell-signaling properties inherent to MBL replacement therapy, which may include induction of immunologic maturation in autologous cells, in addition to simply increasing the serum levels for the extent of half-life of the product [44].

\section{Conclusions}

The MBL-MASP pathway of complement activation is of importance to innate immunity and to response to pathogens. While defects in the pathway have been linked to infectious, vascular and autoimmune disease, no prior reports have stressed the importance of these defects to dermatological disease. We present six cases who had profound defects in the MBL-MASP pathway and who developed serious cutaneous infectious and/or inflammatory disease. It appears that MBL deficiency may contribute to recurrent skin infections and to certain forms of inflammatory skin disease. The mechanisms may relate to the role of this pathway in innate immunity, removal of apoptotic cells and immune complexes. Further study of MBL pathway defects in dermatological disease is required as it may open up treatment options with recombinant MBL protein (when available) for patients with difficult-to-treat dermatological infections.

\section{Written Consent}

Written informed consent was obtained from the patients for publication of this case report and accompanying images. A copy of the written consent is available for review by the Editor-in-chief of this journal.

\begin{abstract}
Abbreviations
MBL: mannose-binding lectin; rhMBL: recombinant MBL; PMBL: plasmaderived MBL; MASP: MBL-associated serine protease; ANA: antinuclear antibody; ESR: erythrocyte sedimentation rate; HIV: human immune deficiency virus; BD: Behcet's disease; MRSA: methicillin-resistant staphylococcus aureus; IgG: immunoglobulin G; PAMP: pathogen-associated molecular patterns; CRP: $C$ reactive protein; CRD: carbohydrate recognition domain; NF- $\kappa$ B: nuclear factor kappaB; TNF- $\alpha$ : tumor necrosis factor alpha; C4: complement component 4; IL-6: interleukin-6; PMN: polymorphonuclear leukocyte.
\end{abstract}

\footnotetext{
Author details

${ }^{1}$ From the Departments of Pathology, Quillen College of Medicine, East Tennessee State University, Johnson City, TN 37614, USA. ${ }^{2}$ Internal Medicine, Quillen College of Medicine, East Tennessee State University, Johnson City, TN 37614, USA. ${ }^{3}$ Division of Allergy Clinical Immunology, Quillen College of Medicine, East Tennessee State University, Johnson City, TN 37614, USA. ${ }^{4}$ The James H. Quillen VA Medical Center, Mountain Home, TN, USA.

\section{Authors' contributions}

CM carried out some literature search and partially drafted the manuscript. SW helped to draft part of the manuscript and proofread the manuscript. MM helped to collect and analyze the data. DSC helped to draft the
}

manuscript, revised it for important intellectual content, and assisted the finalizing of the manuscript. GY was responsible for patient data and analysis. GK conceived and managed the study, drafted the manuscript, managed references, generated figures and tables, and has given final approval of the version to be published. All authors have read and approved the final manuscript.

\section{Competing interests}

The authors declare that they have no competing interests.

Received: 18 December 2009 Accepted: 25 March 2010

Published: 25 March 2010

\section{References}

1. Kupper TS, Fuhlbrigge RC: Immune surveillance in the skin: mechanisms and clinical consequences. Nat Rev Immunol 2004, 4:211-222.

2. Super M, Thiel S, Lu J, Levinsky RJ, Turner MW: Association of low levels of mannan-binding protein with a common defect of opsonisation. Lancet 1989, 2:1236-1239.

3. Steffensen $R$, Thiel $S$, Varming $K$, Jersild C, Jensenius JC: Detection of structural gene mutations and promoter polymorphisms in the mannanbinding lectin (MBL) gene by polymerase chain reaction with sequencespecific primers. J Immunol Methods 2000, 241:33-42.

4. Moller-Kristensen M, Hamblin MR, Thiel S, Jensenius JC, Takahashi K: Burn injury reveals altered phenotype in mannan-binding lectin-deficient mice. J Invest Dermatol 2007, 127:1524-1531.

5. McGirt LY, Beck LA: Innate immune defects in atopic dermatitis. J Allergy Clin Immunol 2006, 118:202-208.

6. lobst ST, Drickamer K: Binding of sugar ligands to $\mathrm{Ca}(2+)$-dependent animal lectins. II. Generation of high-affinity galactose binding by sitedirected mutagenesis. J Biol Chem 1994, 269:15512-15519.

7. Sheriff $S$, Chang CY, Ezekowitz RA: Human mannose-binding protein carbohydrate recognition domain trimerizes through a triple alphahelical coiled-coil. Nat Struct Biol 1994, 1:789-794.

8. Weis WI, Drickamer K: Trimeric structure of a C-type mannose-binding protein. Structure 1994, 2:1227-1240.

9. Madsen HO, Satz ML, Hogh B, Svejgaard A, Garred P: Different molecular events result in low protein levels of mannan-binding lectin in populations from southeast Africa and South America. J Immunol 1998, 161:3169-3175.

10. Bossuyt X, Moens L, Van Hoeyveld E, Jeurissen A, Bogaert G, Sauer K, Proesmans M, Raes M, De Boeck K: Coexistence of (partial) immune defects and risk of recurrent respiratory infections. Clin Chem 2007, 53:124-130.

11. Sorensen GL, Petersen I, Thiel S, Fenger M, Christensen K, Kyvik KO, Sorensen TI, Holmskov U, Jensenius JC: Genetic influences on mannanbinding lectin (MBL) and mannan-binding lectin associated serine protease-2 (MASP-2) activity. Genet Epidemiol 2007, 31:31-41.

12. Stengaard-Pedersen K, Thiel S, Gadjeva M, Moller-Kristensen M, Sorensen R, Jensen LT, Sjoholm AG, Fugger $L$, Jensenius JC: Inherited deficiency of mannan-binding lectin-associated serine protease 2. N Engl J Med 2003, 349:554-560.

13. Dahl M, Tybjaerg-Hansen A, Schnohr P, Nordestgaard BG: A populationbased study of morbidity and mortality in mannose-binding lectin deficiency. J Exp Med 2004, 199:1391-1399.

14. Gomi K, Tokue Y, Kobayashi T, Takahashi H, Watanabe A, Fujita T, Nukiwa T: Mannose-binding lectin gene polymorphism is a modulating factor in repeated respiratory infections. Chest 2004, 126:95-99.

15. Muller S, Keil T, Gruber C, Zitnik SE, Lau S, Wahn U, Witt H, Nickel R: MBL2 variants in relation to common childhood infections and atopy-related phenotypes in a large German birth cohort. Pediatr Allergy Immunol 2007.

16. Ruskamp JM, Hoekstra MO, Rovers MM, Schilder AG, Sanders EA: Mannosebinding lectin and upper respiratory tract infections in children and adolescents: a review. Arch Otolaryngol Head Neck Surg 2006, 132:482-486.

17. Kawasaki N, Kawasaki T, Yamashina I: A serum lectin (mannan-binding protein) has complement-dependent bactericidal activity. J Biochem (Tokyo) 1989, 106:483-489.

18. Krarup A, Sorensen UB, Matsushita M, Jensenius JC, Thiel S: Effect of capsulation of opportunistic pathogenic bacteria on binding of the pattern recognition molecules mannan-binding lectin, L-ficolin, and $\mathrm{H}$ ficolin. Infect Immun 2005, 73:1052-1060. 
19. Eisen DP, Dean MM, Boermeester MA, Fidler KJ, Gordon AC, Kronborg G, Kun JF, Lau YL, Payeras A, Valdimarsson H, Brett SJ, Ip WK, Mila J, Peters MJ, Saevarsdottir S, van Till JW, Hinds CJ, McBryde ES: Low serum mannosebinding lectin level increases the risk of death due to pneumococcal infection. Clin Infect Dis 2008, 47:510-516.

20. Sanders LA, Rijkers GT, Kuis W, Tenbergen-Meekes AJ, de Graeff-Meeder BR, Hiemstra I, Zegers BJ: Defective antipneumococcal polysaccharide antibody response in children with recurrent respiratory tract infections. J Allergy Clin Immunol 1993, 91:110-119.

21. Shi L, Takahashi K, Dundee J, Shahroor-Karni S, Thiel S, Jensenius JC, Gad F, Hamblin MR, Sastry KN, Ezekowitz RA: Mannose-binding lectin-deficient mice are susceptible to infection with Staphylococcus aureus. J Exp Med 2004, 199:1379-1390.

22. Neth $\mathrm{O}$, Jack DL, Johnson M, Klein NJ, Turner MW: Enhancement of complement activation and opsonophagocytosis by complexes of mannose-binding lectin with mannose-binding lectin-associated serine protease after binding to Staphylococcus aureus. J Immunol 2002, 169:4430-4436.

23. Moller-Kristensen M, Thiel S, Sjoholm A, Matsushita M, Jensenius JC: Cooperation between MASP-1 and MASP-2 in the generation of C3 convertase through the MBL pathway. Int Immunol 2007, 19:141-149.

24. Degn SE, Thiel S, Jensenius JC: New perspectives on mannan-binding lectin-mediated complement activation. Immunobiology 2007, 212:301-311.

25. Cunnion KM, Benjamin DK Jr, Hester CG, Frank MM: Role of complement receptors 1 and 2 (CD35 and CD21), C3, C4, and C5 in survival by mice of Staphylococcus aureus bacteremia. J Lab Clin Med 2004, 143:358-365.

26. Netea MG, van Tits $L$, Curfs JH, Amiot F, Meis JF, Meer van der JW, Kullberg BJ: Increased susceptibility of TNF-alpha lymphotoxin-alpha double knockout mice to systemic candidiasis through impaired recruitment of neutrophils and phagocytosis of Candida albicans. Immunol 1999, 163:1498-1505.

27. Quirk CJ, Heenan PJ: Grover's disease: 34 years on. Australas J Dermatol 2004, 45:83-86.

28. Almeida SR: Immunology of Dermatophytosis. Mycopathologia 2008.

29. Dahl MV: Immunological resistance to dermatophyte infections. Adv Dermatol 1987, 2:305-320.

30. Jones HE: Immune response and host resistance of humans to dermatophyte infection. J Am Acad Dermatol 1993, 28:S12-S18.

31. Sohnle PG, Hahn BL: Epidermal proliferation and the neutrophilic infiltrates of experimental cutaneous candidiasis in mice. Arch Dermatol Res 1989, 281:279-283.

32. Brouwer N, Dolman KM, van Houdt M, Sta M, Roos D, Kuijpers TW: Mannose-binding lectin (MBL) facilitates opsonophagocytosis of yeasts but not of bacteria despite MBL binding. J Immunol 2008, 180:4124-4132.

33. Ip WK, Lau YL: Role of mannose-binding lectin in the innate defense against Candida albicans: enhancement of complement activation, but lack of opsonic function, in phagocytosis by human dendritic cells. $J$ Infect Dis 2004, 190:632-640.

34. Fietta P: Behcet's disease: familial clustering and immunogenetics. Clin Exp Rheumatol 2005, 23:S96-105.

35. Koumantaki Y, Stavropoulos C, Spyropoulou M, Messini $H$ Papademetropoulos M, Giziaki E, Marcomichelakis N, Palimeris G, Kaklamanis P, Kaklamani E: HLA-B*5101 in Greek patients with Behcet's disease. Hum Immunol 1998, 59:250-255.

36. Gul A: Behcet's disease: an update on the pathogenesis. Clin Exp Rheumatol 2001, 19:S6-12.

37. Inanc N, Mumcu G, Birtas E, Elbir Y, Yavuz S, Ergun T, Fresko I, Direskeneli H: Serum mannose-binding lectin levels are decreased in behcet's disease and associated with disease severity. J Rheumatol 2005, 32:287-291.

38. Lokitz ML, Zhang W, Bashir M, Sullivan KE, Ang G, Kwon EJ, Lin JH, Werth VP: Ultraviolet-B recruits mannose-binding lectin into skin from non-cutaneous sources. J Invest Dermatol 2005, 125:166-173.

39. Bohlson SS, Fraser DA, Tenner AJ: Complement proteins C1q and MBL are pattern recognition molecules that signal immediate and long-term protective immune functions. Mol Immunol 2007, 44:33-43.

40. Botto M, Dell'Agnola C, Bygrave AE, Thompson EM, Cook HT, Petry F, Loos M, Pandolfi PP, Walport MJ: Homozygous C1q deficiency causes glomerulonephritis associated with multiple apoptotic bodies. Nat Genet 1998, 19:56-59.
41. Siassi $M$, Hohenberger $W$, Riese J: Mannan-binding lectin (MBL) serum levels and post-operative infections. Biochem Soc Trans 2003, 31:774-775.

42. Siassi M, Riese J, Steffensen R, Meisner M, Thiel S, Hohenberger W, Schmidt J: Mannan-binding lectin and procalcitonin measurement for prediction of postoperative infection. Crit Care 2005, 9:R483-R489.

43. Ohlenschlaeger T, Garred P, Madsen HO, Jacobsen S: Mannose-binding lectin variant alleles and the risk of arterial thrombosis in systemic lupus erythematosus. N Engl J Med 2004, 351:260-267.

44. Kilpatrick DC: Stem cell transplantation and MBL replacement therapy. Curr Stem Cell Res Ther 2008, 3:85-87.

doi:10.1186/1476-7961-8-6

Cite this article as: Miller et al: Molecular defects in the mannose binding lectin pathway in dermatological disease: Case report and literature review. Clinical and Molecular Allergy 2010 8:6.

\section{Submit your next manuscript to BioMed Central and take full advantage of:}

- Convenient online submission

- Thorough peer review

- No space constraints or color figure charges

- Immediate publication on acceptance

- Inclusion in PubMed, CAS, Scopus and Google Scholar

- Research which is freely available for redistribution

Submit your manuscript at www biomedcentral com/submit
C Biomed Central 